\title{
ECOLÓGICOS OU CONTROLADOS? CONSTRUINDO DISCURSIVAMENTE O CONSUMIDOR CONSCIENTE
}

\section{ECOLOGICAL OR CONTROLLED? BUILDING DISCURSIVELY CONSCIOUS CONSUMERS}

\section{Fernanda Chagas Borelli}

Doutoranda em Administração pela Universidade Federal do Rio de Janeiro - UFRJ

E-mail: fernandaborelli@gmail.com (Brasil)

\section{Marcus Wilcox Hemais}

Doutorando em Administração pela Universidade Federal do Rio de Janeiro - UFRJ e Professor da Pontifícia Universidade Católica do Rio de Janeiro - PUC-Rio

E-mail: mhemais@gmail.com (Brasil)

\section{Pedro Ivo Rogedo Costa Dias}

Doutorando em Administração pela Universidade Federal do Rio de Janeiro - UFRJ E-mail: tannervoldken@gmail.com (Brasil)

REMark - Revista Brasileira de Marketing, São Paulo, v. 11, n. 2, p. 18-42, maio/ago.2012. 


\title{
ECOLÓGICOS OU CONTROLADOS? CONSTRUINDO DISCURSIVAMENTE O CONSUMIDOR CONSCIENTE
}

\begin{abstract}
RESUMO
Num contexto em que o consumo vem sendo apontado como um dos grandes responsáveis pela destruição de recursos e pelo desequilíbrio do clima terrestre, o consumidor vem sendo chamado para fazer a sua parte. Surge, então, um grupo de consumidores preocupados com o efeito de suas compras no mundo exterior - o que chamamos aqui de consumidores conscientes. Este trabalho procura auxiliar no entendimento dos discursos dominantes sobre o consumo consciente, investigando como o consumidor consciente, suas motivações, suas práticas e suas dificuldades são discursivamente construídos pelos demais consumidores. A pesquisa baseou-se em um exercício projetivo inspirado no estudo de Belk, Deninney e Eckhardt (2005) respondido por 37 alunos de uma universidade privada localizada no subúrbio da cidade do Rio de Janeiro. Os respondentes delinearam duas construções discursivas do consumidor consciente, construídas a partir de uma forte dualidade com o que chamam de "consumidor inconsciente". Motivações, mudanças de comportamento e dificuldades enfrentadas por estes consumidores são discutidas e, com base nelas, são sugeridas aplicações gerenciais e caminhos de pesquisa futura.
\end{abstract}

Palavras-chave: Consumo consciente; Consumidor consciente; Técnica projetiva.

\section{ECOLOGICAL OR CONTROLLED? BUILDING DISCURSIVELY CONSCIOUS CONSUMERS}

\begin{abstract}
In a context in which consumption has been identified as largely responsible for the destruction of resources and the imbalance of the Earth's climate, consumers are being asked to take action. Thus a group of consumers concerned about the effects of their purchases in the outside world has appeared - a group we shall call conscious consumers. This work aims to help understand the dominant discourses on conscious consumption, investigating how consumers discursively construct the conscious consumer, the motivations, the practices, and the difficulties. The research was based on a projective exercise inspired by Belk, Deninney and Eckhardt "s (2005) study. Thirty-seven students at a private university located in the suburb of the city of Rio de Janeiro took part on this exercise. Respondents outlined two discursive constructions for the conscious consumer, constructed from a strong duality with what they called the "unconscious consumer." Motivations, behavior changes, and difficulties faced by these consumers were discussed and inspired management applications and paths for future research.
\end{abstract}

Keywords: Conscious consumption; Conscious consumer; Projective techniques.

REMark - Revista Brasileira de Marketing, São Paulo, v. 11, n. 2, p. 18-42, maio/ago.2012. 


\section{INTRODUÇÃO}

O consumo tem sido atacado como um dos grandes responsáveis pelo que vem se configurando um dos maiores problemas que a humanidade enfrenta: o desequilíbrio do clima terrestre. Com base nesta ideia, a redução dos níveis de consumo em caráter global tem sido colocada como condição sine qua non para a continuidade da vida humana no planeta (Huneke, 2005; Miller, 2007; Worldwatch Institute, 2010). Emerge daí um discurso compartilhado por instituições tão diversas como ONGs e ativistas, mídias e governos que coloca os indivíduos como corresponsáveis por estas questões e os convoca a fazer a sua parte, alterando a forma que consomem (Wheeler, 2012).

Este contexto parece propício para o surgimento de um 'novo' consumidori, aquele preocupado com os efeitos de suas compras no mundo exterior. Em consequência, despontam uma série de trabalhos que têm nestes consumidores seu objeto de estudo. Examinando do anticonsumo ao consumo ético, passando pelo consumo verde, responsável, consciente ou sustentável, pela simplicidade voluntária e pela culture jammer (Cherrier, 2005; 2006; 2007; 2009; Connolly \& Prothero, 2008; Etzioni, 2004; Kozinets \& Handelman, 2004; Mcdonald, Oates, Young \& Hwang, 2006; Ozcaglar-Toulouse, 2007; Szmigin, Carrigan, \& McEachern, 2009, entre outros), seus autores buscam entender o como e o porquê de comportamentos que, na contramão da sociedade atual - uma "sociedade de consumidores" (Bauman, 2008, p.19), levam em consideração aspectos ambientais, sociais, políticos e até mesmo espirituais das práticas de consumo.

Estes estudos colocam sob escrutínio, por exemplo, características demográficas destes consumidores (e.g. Huneke, 2005) e motivações para seu comportamento (e.g. Pepper, Jackson, \& Uzzell, 2009; Zavestoski, 2002), significados atribuídos ao comportamento de consumo ético e responsável e sua contribuição na construção da identidade (e.g. Connolly \& Prothero, 2003; Ozcaglar-Toulouse, 2007), o processo de internalização destes discursos e práticas por parte dos consumidores (Cherrier, 2005) e, ainda, antecedentes da resistência ao consumo (Cherrier, 2009). Em comum a estes trabalhos está a busca por uma maior compreensão do comportamento deste 'novo' consumidor.

Reconhecemos a importância do esforço destes estudiosos para o aprofundamento do entendimento da cultura de consumo, da sociedade atual e suas transformações. No entanto, diante da necessidade de uma redução massiva do consumo, parece importante entender não apenas atitudes e comportamento destes 'novos' consumidores, mas, também, como os demais

REMark - Revista Brasileira de Marketing, São Paulo, v. 11, n. 2, p. 18-42, maio/ago.2012. 
consumidores percebem este esforço. Entendemos que este 'outro olhar' traria à tona discursos e sistemas de representação (Hall, 1997) dominantes acerca do consumo consciente.

Este trabalho, portanto, procura auxiliar no entendimento dos discursos dominantes sobre o consumo consciente, investigando como o consumidor consciente, suas motivações, suas práticas e suas dificuldades são discursivamente construídos pelos demais consumidores. $\mathrm{O}$ estudo baseia-se em um exercício projetivo feito com alunos de graduação de uma universidade privada localizada no subúrbio da cidade do Rio de Janeiro. Assim como em Moisander e Pesonen (2002), presumimos que, neste exercício, os alunos se utilizariam dos discursos ou sistemas de representação (Hall, 1997) dominantes, negociando e reproduzindo significados culturalmente compartilhados sobre o consumo consciente.

O entendimento de percepções e dificuldades associadas ao comportamento de consumo consciente pode apontar questões a serem abordadas e caminhos a serem traçados por empresas e por organizações não-governamentais e outras instituições que tratam do tema e, adicionalmente, inspirar a configuração de propostas para políticas públicas.

\section{REFERENCIAL TEÓRICO}

O crescente interesse do mercado por temas ambientais fez surgir uma série de designações para o consumo influenciado por questões ecológicas (Barros, Tucci, \& Costa, 2010). Dentre elas, "consumo verde" (Connolly \& Prothero, 2008), "consumo consciente" (Szmigin et al., 2009), "consumo responsável” (Ozcaglar-Toulouse, 2007) e "consumo ético" (Harrison, Newholm, \& Shaw, 2005). Algumas destas práticas de consumo abrangem preocupações que vão além dos impactos ambientais, incluindo questões sociais, políticas e até mesmo de cunho religioso e espiritual.

Entendemos que estes termos gravitam em torno da ideia de um "conjunto de atos voluntários, situados na esfera do consumo, realizados a partir da consciência das consequências do consumo julgadas como negativas ao mundo exterior, essas consequências emergindo, portanto, não da funcionalidade das compras nem de interesse pessoal imediato" (OzcaglarToulouse, 2007, p. 422-423). Portanto, não se pretende aqui fazer uma diferenciação detalhada entre eles, mas trazer os achados dos estudos que investigam este 'novo consumidor'.

Neste trabalho reunimos estes 'novos consumidores' em um grande grupo daqueles indivíduos que tem em comum a preocupação com o impacto que seu consumo pode exercer no

REMark - Revista Brasileira de Marketing, São Paulo, v. 11, n. 2, p. 18-42, maio/ago.2012. 
mundo exterior (Harrison et al. 2005), sob o termo consumidor consciente (Szmigin et al., 2009) - expressão que vem sendo difundida no Brasil através do Instituto Akatuii (Barros \& Costa, 2008).

Szmigin et al. (2009) sugerem que mídia, cientistas e especialistas não conseguem fornecer aos consumidores um consenso sobre prescrições do que seria um comportamento ético ou consciente. Informações e pareceres são muitas vezes contraditórios (Cherrier, 2007). Assim, nem sempre o que é considerado adequado por um indivíduo o é para outro (Szmigin et al., 2009).

Alguns autores sugerem que os consumidores conscientes adotam comportamentos que, de alguma forma, aliviam suas preocupações. Sentem-se compelidos a fazer algo com relação aos problemas sociais e ambientais que percebem, o que sugere que esta forma de consumo seria um meio de aplacar culpas ou reduzir responsabilidades em relação aos problemas ambientais e sociais (Barros e Ayrosa, 2012; Barros et al., 2010; Shaw e Newholm, 2002).

Mas este consumidor percebe dificuldade em ser totalmente ético ou 'fazer tudo certo', o que pode acarretar sentimentos de fracasso e ansiedade (Shaw \& Newholm, 2002; Szmigin et al., 2009).

Ozcaglar-Toulouse (2007) e Szmigin et al. (2009) colocam estas práticas de consumo como um projeto reflexivo em andamento, no qual há um processo infindável de avaliação pessoal. Segundo Szmigin et al. (2009), mesmo estando conscientes das questões éticas e compreendendo alguns dos conflitos motivacionais que experimentam, muitas vezes estas preocupações não conseguem superar questões relacionadas a gosto, preço ou conveniência nas escolhas de consumo. Atributos éticos são avaliados pelos consumidores juntamente com outros atributos relevantes para sua tomada de decisão, que, em alguns casos, podem predominar no momento da escolha do que consumir (Shaw \& Clark, 1998 apud Szmigin \& Carrigan, 2006). Segundo Belk et al. (2005), já se sabe que o comportamento ético pode ser afetado pela natureza do produto e do preço a ser pago e que, algumas vezes, o comportamento ético não é suficiente para justificar a compra de produtos inferiores.

Comportamento e atitudes conscientes ou éticas podem impactar as relações familiares e pessoais do indivíduo (Shaw \& Newholm, 2002). Szmigin et al (2009) sugerem que possíveis inconsistências no comportamento de compra dos consumidores conscientes são o meio encontrado por eles para gerenciar dificuldades relacionadas à acomodação de seus gostos e de suas famílias, seus orçamentos e suas preocupações éticas. Alguns consumidores podem ainda experimentar certa flexibilidade como uma forma de prevenção contra culpas e neuroses, ao

REMark - Revista Brasileira de Marketing, São Paulo, v. 11, n. 2, p. 18-42, maio/ago.2012. 
afirmarem que 'não são perfeitos' (Shaw e Newholm, 2002). Apesar de preocuparem-se com diversas questões éticas, podem negligenciar algumas destas questões, priorizando outras, durante a compra como uma estratégia para conseguir administrar razoavelmente suas escolhas.

Ozcaglar-Toulouse (2007) observa que o consumidor experimenta um conflito entre o prazer pessoal derivado do ato de consumir e o sofrimento causado pelo seu impacto negativo sobre o ambiente, sobre as condições em que alguns produtores vivem, sobre desigualdades sociais, dentre outros aspectos. A autora propõe, a partir do framework de Hirschman (1970), três estratégias desenvolvidas pelo indivíduo na tentativa de resolver estes conflitos internos: (1) Saída: o consumidor decide renunciar ao ato de consumo e ao prazer associado a ele com o objetivo de evitar a cumplicidade com suas consequências (exemplos disto são os comportamentos anti-consumo e a simplicidade voluntária); (2) Lealdade: permite à pessoa desempenhar um ato de consumo enquanto tenta minimizar suas consequências negativas e/ou tenta extrair um benefício máximo do produto/serviço. Ou seja, o consumidor permanece fiel ao consumo e tentar melhorar seu funcionamento. (exemplos incluem a compra de produtos éticos e a reciclagem); (3) Voz: aqui, o consumidor parece não sentir qualquer obrigação em resolver o conflito carregado pelo seu ato de consumo, mas, ao contrário, tenta transformar todo o sistema de uma forma externa como, por exemplo, através de boicotes.

Indivíduos são expostos a informações sobre incertezas ecológicas, desigualdades sociais e instabilidade global e sobre a importância do consumo ético, ou da redução do consumo. Mas, o que faz com que internalizem estes discursos e transformem suas práticas de consumo? Cherrier (2005) sugere que a internalização passa por três estágios: a desestabilização, o deslocamento e a descoberta.

A desestabilização está associada a eventos disparadores, imprevisíveis e incontroláveis, desestabilizando a visão de vida e de existência. Tais eventos seriam como 'insights' transformadores de vida resultantes de uma profunda emoção ou uma experiência afetiva. Estes eventos desestabilizam a segurança ontológica dos indivíduos, fazendo-os "questionar a natureza de sua existência e identidade". Este é o estágio de descolamento, em que os indivíduos se enxergam como "vítimas indefesas das circunstâncias externas" e se sentem desorientados, “impotentes e solitários, expressando severa ansiedade e medo" (p. 602). O terceiro estágio, a descoberta, implica no descobrimento do comportamento de consumo ético através de exemplos de vida de outros, abrindo a possibilidade de uma nova identidade e de novas práticas de consumo. Ansiedade e medo são vencidos, e é encontrada legitimação para mudanças no estilo de vida de consumo.

REMark - Revista Brasileira de Marketing, São Paulo, v. 11, n. 2, p. 18-42, maio/ago.2012. 
Desta forma, a internalização de discursos e práticas de consumo ético não emerge apenas a partir de reflexões ou da cognição racional, mas sim a partir de um evento transformador que leva o indivíduo a (re)avaliar o seu ambiente e (re)formular sua vida. Em resumo, este processo dá-se através das relações com os outros e com o mundo (Cherrier, 2005). Assim, este comportamento de consumo seria produto de uma coprodução do individual e do coletivo; seria um "conceito dinâmico e socialmente construído pelo qual consumidores são mutuamente constituídos por sua própria agência e pelo seu ambiente estrutural de mudança" (Cherrier, 2005, p. 603).

Estes eventos 'desestabilizadores' (Cherrier, 2005) ou 'acontecimentos fundadores' (Ozcaglar-Toulouse, 2007) podem se constituir, por exemplo, de crise na vida profissional, mudança para uma casa nova, eventos sociais, crises domésticas ou viagens, e são colocados pelos autores como o ponto de transição ou de virada que origina a orientação para o consumo consciente, abrindo caminho para a reconstrução da identidade.

Ozcaglar-Toulouse (2007) classifica seus pesquisados em dois grupos principais: aqueles para os quais o consumo assume o significado de um ato de "conformidade moral" (p. 434) e aqueles cujo consumo representa "atos críticos" (Ozcaglar-Toulouse, 2007, p. 434). Os atos críticos, por sua vez, podem ser divididos entre os atos de essência política - usar o consumo a fim de mudar o mundo através da militância pela e a fim de influenciar a sociedade - e atos com objetivo libertador - consumidores que querem ficar de fora do "sistema" de consumo imposto a eles.

O estudo de Cherrier (2009) com simplificadores voluntários e culture jammers pode ajudar a iluminar significados por trás do consumo consciente. A autora identificou dois grandes temas relacionados aos comportamentos resistentes de seus entrevistados: "viver em um mundo incontrolável”, que coloca os problemas ecológicos e desigualdades sociais como consequências do consumo; e a "solidão emocional", que coloca a cultura de consumo como responsável pelos comportamentos de consumo obsessivos, que estão relacionados ao que a autora chama de um sentimento de 'solidão emocional'.

Dentro do primeiro tema, "viver em um mundo incontrolável", o discurso mostra que se deve resistir ao consumo 'extravagante' e 'completamente desnecessário' e ao 'desperdício' promovidos pela cultura de consumo, pois causam impacto ambiental/social no mundo exterior. Cherrier (2009) relaciona este aspecto ao discurso cultural do 'consumo explorativo', que representa o consumo como exploração e exaustão de recursos naturais e manipulação de desigualdades sociais. Aqui, "a crítica do consumo é dirigida mais aos produtores e negócios do

$\overline{\text { REMark - Revista Brasileira de Marketing, São Paulo, v. 11, n. 2, p. 18-42, maio/ago.2012. }}$ 
que aos consumidores" (p. 185). Lojas de departamento e shopping centers, por exemplo, são acusados de desperdiçarem recursos naturais, esgotarem o excesso de produção e promoverem desigualdades sociais.

A resposta ao consumo 'explorativo' seria o 'consumo político', que "expressa a ideia de que cada ação individual pode influenciar o mundo em que vivemos" e "luta contra o poder dominante". As práticas de consumo político expressam "resistência contra o poder do "consumo de massa' ou de 'grandes corporações"”. Os consumidores reelaboram "os significados do consumo em direção à justiça, igualdade e participação", buscam influenciar os outros, desenvolvendo sua consciência, e são orientados para a mudança externa (Cherrier, 2009, p. 186).

No segundo tema, 'solidão emocional', a aquisição de bens "desnecessários" é descrita como um comportamento "viciante", associado ao "consumo descontrolado". A acumulação material resultante deste tipo de consumo resulta em uma vida desgastante e infeliz. Esta dependência do consumo é posta como uma resposta à vida em um "mundo vazio". Como coloca uma das entrevistadas do estudo: o consumo é utilizado como uma "medicação emocional" (Cherrier, 2009, p. 185).

O tema da solidão emocional relaciona-se aos discursos culturais sobre 'consumo posicional'. O consumo posicional considera que o ato de consumir ou "ostentar objetos materiais oferece um senso de self que os outros reconhecem e aceitam", ou seja, entende a prática de consumo como "essencialmente estrutural", como forma de integração social. A resposta ao 'consumo posicional' é o desenvolvimento do 'consumo criativo', no qual "os consumidores não mais adquirem, consomem e descartam objetos materiais em resposta às expectativas dos outros” (p.187). O ‘consumo criativo' não intenciona negar a cultura do consumo; ao contrário, fundamenta-se na cultura de massa e na estrutura social como meio de buscar da individualidade. Diferentemente do consumidor político, o consumidor criativo não pretende influenciar os outros nem alterar o sistema. Ele "personaliza seu estilo de vida de consumo como forma de expressar e construir sua identidade" (Cherrier, 2009, p. 188).

REMark - Revista Brasileira de Marketing, São Paulo, v. 11, n. 2, p. 18-42, maio/ago.2012. 


\section{METODOLOGIA}

Este estudo pretende contribuir para o entendimento da cultura de consumo e de um de seus fenômenos mais recentes: o consumo preocupado com impactos exteriores. Optou-se por trazer uma perspectiva diferente da habitual. Enquanto os estudos que vem sendo desenvolvidos neste campo têm como foco o entendimento deste 'novo consumidor', que chamamos aqui de consumidor consciente, este artigo preocupa-se com os discursos dominantes sobre este consumidor.

Buscou-se neste estudo entender como o consumidor consciente, suas motivações, suas práticas e suas dificuldades são discursivamente construídos pelos demais consumidores. Procurou-se, portanto, entender como os pesquisados caracterizam o consumidor consciente; a que motivações associam a seu comportamento; que práticas e mudanças de comportamento relacionam ao consumidor consciente; e que dificuldades precisam enfrentar.

A pesquisa utilizou a técnica projetiva e foi inspirada no estudo de Belk, Deninney e Eckhardt (2005), que recorreu a métodos projetivos para investigar a adoção ou não de comportamento de consumo ético.

O uso de técnicas projetivas é útil em situações de pesquisa em que os informantes possam se sentir encorajados a formular respostas socialmente aceitas, de forma a impressionar ou agradar o pesquisador. A técnica projetiva propicia a obtenção de informações livres deste viés social, permitindo ao pesquisador desvendar as impressões reais dos indivíduos sobre o assunto pesquisado, obtendo respostas mais completas, aprofundadas, verdadeiras e honestas dos participantes do que seria possível em questionamentos diretos (Levy, 1985 apud Boddy, 2005; Rook, 2006; Steinman, 2009).

Ao invés de perguntar diretamente aos participantes sobre seus comportamentos e motivações de compra, os métodos projetivos utilizam perguntas com base em outras pessoas ou situações imaginárias (Will, Eadie, \& Macaskill, 2005). Ao permitir que o respondente projete seus próprios pensamentos, sentimentos, problemas ou dificuldades em outra pessoa, as técnicas projetivas permitem contornar defesas conscientes, facilitando a articulação de pensamentos que, de outra forma, estariam reprimidos ou retidos (Boddy, 2005). Para Gordon e Langmaid (1990 apud Boddy, 2005) “a 'projeção' seria uma tendência a imbuir objetos ou eventos de características ou significados derivados de desejos ou sentimentos daquele que projeta" (p. 241).

REMark - Revista Brasileira de Marketing, São Paulo, v. 11, n. 2, p. 18-42, maio/ago.2012. 
A pesquisa contou com 37 respondentes, alunos de uma universidade privada localizada no subúrbio da cidade do Rio de Janeiro. Inspirados em Moisander e Pesonen (2002), entendemos que, em seus relatos, os alunos se utilizariam dos discursos ou sistemas de representação (Hall, 1997) dominantes, negociando e reproduzindo significados culturalmente compartilhados sobre o consumo consciente.

Ressalta-se que a universidade em questão é considerada uma escola de segunda linha, atendendo a alunos que não conseguiram acesso às melhores universidades, seja por deficiências em sua formação básica, seja por falta de recursos para arcar com os custos das melhores escolas. A idade dos participantes variava entre 18 e 59 anos, porém, a maioria concentrava-se entre 18 e 34 anos. Com relação à classe econômica, a maior parte dos respondentes estava classificada como classe B1 ou B2, embora o estudo também tenha contemplado alguns alunos das classes A1, A2 e C1 - de acordo com o Critério Brasil.

No exercício projetivo, foi solicitado aos participantes que escrevessem uma descrição das características e traços de personalidade de uma personagem - Ana, uma vizinha do respondente - que havia decidido se tornar uma consumidora consciente. A personagem foi definida como uma vizinha no intuito de apresentar um indivíduo de status semelhante ao do respondente (Belk et al., 2005).

Além de uma descrição detalhada da personagem, era pedido que os respondentes apontassem as motivações para sua decisão e relatassem a história de Ana e de sua transformação no máximo de detalhes possível. Na sequência, era pedido que descrevessem as mudanças de comportamento e os novos hábitos que seriam adotados pela personagem. Por fim, deveriam indicar as mudanças mais difíceis/ fáceis para a personagem e explicar o porquê desta dificuldade / facilidade.

A utilização de situação projetiva teve como objetivo evitar que o participante se sentisse pressionado a responder 'corretamente' às perguntas, o que poderia ocorrer em um questionário com interpelações diretas do tipo 'O que você entende por consumo consciente?' ou 'Que práticas você associa ao consumo consciente?'. A projetiva retirou o foco do respondente, colocando-o sobre a personagem, o que pareceu deixar o participante mais à vontade para formular suas respostas.

Apesar da técnica projetiva buscar entendimento sobre emoções e significados sobre um fenômeno que possa ter ocorrido com um consumidor, não é necessário que ele o tenha vivenciado para que as informações coletadas sejam válidas para o propósito da pesquisa (Rook, 2006). Em todos os casos, foi informado aos participantes de que não havia resposta correta e

REMark - Revista Brasileira de Marketing, São Paulo, v. 11, n. 2, p. 18-42, maio/ago.2012. 
que esta deveria ser feita de acordo com seu conhecimento e imaginação. Apenas uma das respostas foi desconsiderada no estudo por apresentar dificuldade de entendimento por parte dos pesquisadores.

As respostas variaram em tamanho, de algumas poucas linhas a mais de uma página. Os respondentes tenderam a dar respostas mais longas ao serem perguntados sobre a descrição da personagem, suas motivações e sua história. As questões que investigaram as mudanças de comportamentos e novos hábitos da consumidora consciente tiveram, em geral, respostas mais breves, o que sugere pouca familiaridade dos pesquisados com o tema.

Para a análise dos dados, todos os questionários foram lidos e organizados em um quadro, de cerca de 12 páginas, contendo as respostas de cada respondente organizadas em grandes temas. Isto facilitou a identificação de padrões de resposta e de respostas dissonantes (Spiggle, 1994), além de permitir a comparação mais rápida entre respondentes auxiliando na criação de categorias de análise. Tais categorias foram, posteriormente, comparadas com a literatura sobre o tema. Segundo Gummeson (2005), a comparação constante entre achados de pesquisas permite que padrões comecem a ser delineados, com o objetivo de se tornarem conceitos, categorias e, eventualmente, teorias.

\section{ANÁLISE E RESULTADOS}

A partir da análise dos questionários foi possível distinguir dois grupos de respostas: duas construções distintas do consumidor consciente. Um grupo de respondentes coloca o consumo consciente sob uma perspectiva individual e predominantemente financeira, ou seja, o consumo consciente é visto como o oposto do consumo compulsivo e do descontrole financeiro. Denominamos os consumidores conscientes construídos por este grupo como individualistas calculistas.

O outro grupo de respondentes associa consumo consciente predominantemente à preocupação com os impactos do consumo no mundo exterior, sobretudo os ambientais. Nomeamos os consumidores conscientes retratados por este grupo de coletivistas ecológicos. Alusões ao consumo compulsivo também surgem neste grupo, porém com foco maior em seus efeitos no meio ambiente. Enquanto em alguns aspectos o consumidor consciente concebido no discurso destes dois grupos se aproximam, em outros parecem bastante distantes - o que será explorado nas seções a seguir.

REMark - Revista Brasileira de Marketing, São Paulo, v. 11, n. 2, p. 18-42, maio/ago.2012. 


\subsection{O CONSUMIDOR INCONSCIENTE}

Para construir o consumidor consciente, alguns respondentes recorreram a uma dualidade entre este consumidor e o que seria seu oposto: o "consumidor inconsciente". Começam seus relatos, portanto, construindo este consumidor "inconsciente", que seria representado por Ana, a personagem, antes de sua mudança de comportamento. O termo "inconsciente" parece ter sido usado pelos respondentes no sentido de 'não ser feito conscienciosamente', 'não ter noção do que faz', 'não proceder com conhecimento claro do que faz' e 'feito de forma irresponsável', ou mesmo, 'leviana'. O uso de tal expressão pode ser sinal de pouca familiaridade dos informantes com a noção de "consumo consciente", uma vez que nem a literatura e nem mesmo o Instituto Akatu utilizam-na. Por ter sido recorrentemente citado, buscou-se analisar nesta seção o que objetos, práticas, atitudes - os informantes associam ao "consumidor inconsciente".

Para os respondentes que descrevem o consumidor consciente como individualista calculista, a expressão "consumidor inconsciente" é utilizada para fazer referência a um consumidor compulsivo. Talvez por isso, o consumo - mais especificamente, as compras - seja descrito por este grupo como uma "tentação" e, como sugere o termo compulsão, algo difícil de evitar, resistir ou controlar. O "shopping", o "cartão de crédito" e, em menor frequência, as "promoções", o "cheque especial", os "empréstimos", as "lojas", as "vitrines" e até as "marcas" parecem representar ícones desta "tentação".

A tentação é tamanha que exigiria atitudes extremas como "parar de andar com", "aposentar de vez", "desativar" ou "quebrar todos" os cartões de crédito, "bloquear os empréstimos", "parar de frequentar o shopping", "negar-se ao passeio no shopping com as amigas" e mesmo "evitar as amigas", pois o encontro com elas significa "compras".

Estes respondentes parecem identificar uma tensão entre a "tentação" do consumo e a racionalidade financeira, como sugerem os seguintes trechos de respostas: "o limite do cartão de crédito é só um aviso que dali você não passa, não que você tem que gastar até ali sempre"; “aprender a não comprar porque está muito barato e sim porque precisa".

O consumidor "inconsciente" retratado por eles é fútil e vaidoso, "não pensa no futuro" e, por isso, "não constrói nada, só gasta". Os objetos de consumo mais associados a ele são roupas, sapatos, bolsas, perfumes e jóias - é oportuno lembrar que a personagem criada é uma mulher -, e tudo mais que seja considerado "fútil", "supérfluo", “desnecessário" e "sem utilidade".

REMark - Revista Brasileira de Marketing, São Paulo, v. 11, n. 2, p. 18-42, maio/ago.2012. 
O comportamento de consumo "inconsciente" - de valência claramente negativa, a ponto de estar associado a "maus costumes" - é descrito por um dos respondentes como "irracional" e "exagerado", e inclui "comprar em excesso", "sem preocupação", "tudo que vê", de forma “impulsiva”, "sem limites". Isto significa "esbanjar", "estourar limites". Este "descontrole financeiro" causa não apenas "dívidas", mas também "culpa na consciência".

A ideia de "medicação emocional" que aparece em Cherrier (2009) surge na descrição que um dos respondentes faz de Ana quando consumidora "inconsciente". Neste caso, a motivação apontada para a alteração de comportamento foi uma "complicada desilusão amorosa". Neste relato, a personagem, antes da mudança, era gordinha, com problemas de autoestima, e sentia-se "muito bem quando estava fazendo compras", "correndo para o shopping" quando "estava triste" ou com "problemas". Esta descrição parece se inserir bem no discurso identificado por Cherrier (2009) que coloca o consumo como produto de solidão emocional. Segundo o respondente, a personagem vivia em um "mundo de imaginação" e seu descontrole de gastos era fruto de "falta de amor próprio".

A caracterização do consumidor "inconsciente" pelo grupo que concebe o consumidor consciente como coletivista ecológico - guarda diversas semelhanças com a do grupo anterior. Porém, além de comprar o "supérfluo", o "fútil" e o "desnecessário", este "consumidor de carteirinha", como descreve um dos respondentes, “compra produtos para tornar-se bem visto na sociedade" - o que remete ao conceito de 'consumo posicional' de Cherrier (2009). Além de "roupas, sapatos e perfumes", os bens relacionados a ele por este grupo incluem o carro, o fast food e as bebidas alcoólicas. Porém não é o cartão de crédito, mas as sacolas plásticas, a imagem representativa do "consumidor inconsciente" para este grupo.

Nas descrições deste grupo, surge a palavra "desperdício", notadamente de água e energia: "porta da geladeira aberta"; "horas no banho"; "deixar luz acesa e torneira de água aberta". O "consumidor inconsciente" também é descrito como aquele que "não separa lixo", "joga lixo na rua", "queima folhas secas", "usa papel comum" ao invés de reciclado e "imprime desnecessariamente". O discurso construído por estes respondentes indica que além de "compulsivo" e "descontrolado", o "consumidor inconsciente" parece ser egoísta, pois "só se preocupa consigo mesmo", além de estar "desligado de tudo que está acontecendo", incluindo "a escassez de recursos naturais".

Algumas expressões dos respondentes deste grupo sugerem ainda uma aproximação entre a transformação da personagem e uma conversão religiosa. Enquanto o consumo é associado a "tentação" e gera "culpa", o consumo consciente é referido como “o caminho". Ele exige

REMark - Revista Brasileira de Marketing, São Paulo, v. 11, n. 2, p. 18-42, maio/ago.2012. 
"sacrifício" em troca do "bem da sociedade". Os consumidores conscientes coletivistas ecológicos envolvem-se em um trabalho de "convencer" ou "conscientizar" os outros - quase como um 'pregador', o que aproxima esta descrição do consumo como ato crítico de essência política, identificado por Ozcarglar-Toulouse (2007).

\subsection{CONSTRUINDO O CONSUMIDOR CONSCIENTE}

É possível perceber que, nas duas construções do consumidor consciente, a dicotomia entre descontrole e controle domina as descrições do comportamento de 'antes e depois' da personagem. O comportamento anterior à mudança é descrito por expressões como "descontrole financeiro" ou "de gastos", impulsividade, "sem limites", "estourar limites", "excesso de compras", "consumo compulsivo", "comprar tudo que vê". Já o comportamento consciente pressupõe "moderação", "disciplina", "resistir às tentações do dia-a-dia", "policiar-se no dia-adia", "controlar-se", “controlar o desperdício"; requer "pensar antes", "planejar", "pesquisar", "avaliar", "conhecer" e "informar-se".

Alinhado às visões de que este tipo de consumo é um projeto reflexivo em andamento (Ozcaglar-Toulouse, 2007; Szmigin et al., 2009), um dos respondentes sumariza bem a necessidade de autocontrole inerente ao consumo consciente: "É como um tratamento de $\mathrm{AA}^{\mathrm{iii}}$ : todo dia é uma nova batalha". Esta necessidade de controle também foi encontrada por Shaw e Newholm (2002) entre seus pesquisados.

Apesar de Szmigin et al. (2009) e Cherrier (2007) apontarem para a profusão de informações contraditórias oferecidas ao consumidor, o caminho de autocontrole e reflexividade dos consumidores conscientes coletivistas ecológicos requer informação e conhecimento, apontam os respondentes. Alguns deles parecem sugerir que ser um consumidor consciente não é para qualquer um: exige informação. Um deles, ao descrever a motivação da personagem para sua mudança explica que uma "conversa com amigos" gerou sua "curiosidade" e fez "com que buscasse informações em jornais, revistas e Internet". Talvez por conta desta necessidade de informação, parte dos informantes caracteriza a personagem como "bem instruída", "graduada", "pós-graduada", “antenada", “atualizada", "bem informada”, “esclarecida”, de "bom nível social-cultural"'.

As informações necessárias ao consumidor consciente coletivista ecológico podem vir de "campanhas pelo meio ambiente" de ONGs e ambientalistas, "palestras sobre consumo consciente" e ações governamentais que estimulem a adoção de comportamento de consumo

REMark - Revista Brasileira de Marketing, São Paulo, v. 11, n. 2, p. 18-42, maio/ago.2012. 
consciente - sejam elas em forma de "publicidade" ou de projetos educacionais (um dos respondentes menciona um "projeto do governo onde [a personagem] apresnde sobre reciclagem e receitas de reaproveitamento de alimentos"). A mídia aparece bastante presente nos discursos. Alguns respondentes falam de "programas de rádio" ou de TV - como o "Fantástico" - falando sobre, por exemplo, o "agravamento da realidade ambiental do planeta" ou alguma "pesquisa dizendo que sacolas [de plástico] demoram muitos anos para se deteriorar”. Estas foram algumas das motivações apontadas para a transformação da personagem em uma consumidora consciente coletivista ecológica.

No caso dos individualista calculista, aparece com força a ideia de reflexão pessoal motivando a transformação. Nesta linha, um dos respondentes explica que Ana "enxergou que tudo é passageiro", enquanto um outro menciona que a personagem "percebeu que tinha perdido uma fortuna em coisas fúteis".

Para alguns respondentes, é preciso mais do que informação ou pura reflexão. Eles parecem concordar com Cherrier (2005) ao apontarem algum evento como o disparador da mudança da personagem. Eventos disparadores aparecem nos discursos que constroem tanto o consumidor consciente coletivista ecológico quanto o individualista calculista. A personagem tornou-se uma consumidora consciente coletivista ecológica, após ela ter se separado do marido, ou ter passado por uma experiência traumática na adolescência, ou ter participado em projetos sociais, ou mesmo ter ficado assustada com o resultado de um questionário sobre consumo consciente que respondeu. Nos relatos sobre individualista calculista é frequente a ideia de um forte endividamento desencadeando a transformação da personagem. Mas, outros respondentes falam da mudança ter ocorrido após Ana ter ido morar sozinha, ou ter passado por uma desilusão afetiva, ou ter perdido o 'patrocínio' do pai. Assim como encontrado por Cherrier (2005) e Ozcaglar-Toulouse (2007), os respondentes parecem indicar a necessidade de um evento desestabilizador, que faça com que a personagem questione e reconstrua sua identidade de então.

A figura 1 sumariza os principais motivadores do comportamento de consumo consciente apontados pelos respondentes.

REMark - Revista Brasileira de Marketing, São Paulo, v. 11, n. 2, p. 18-42, maio/ago.2012. 
Figura 1 - Principais motivadores do comportamento de consumo consciente

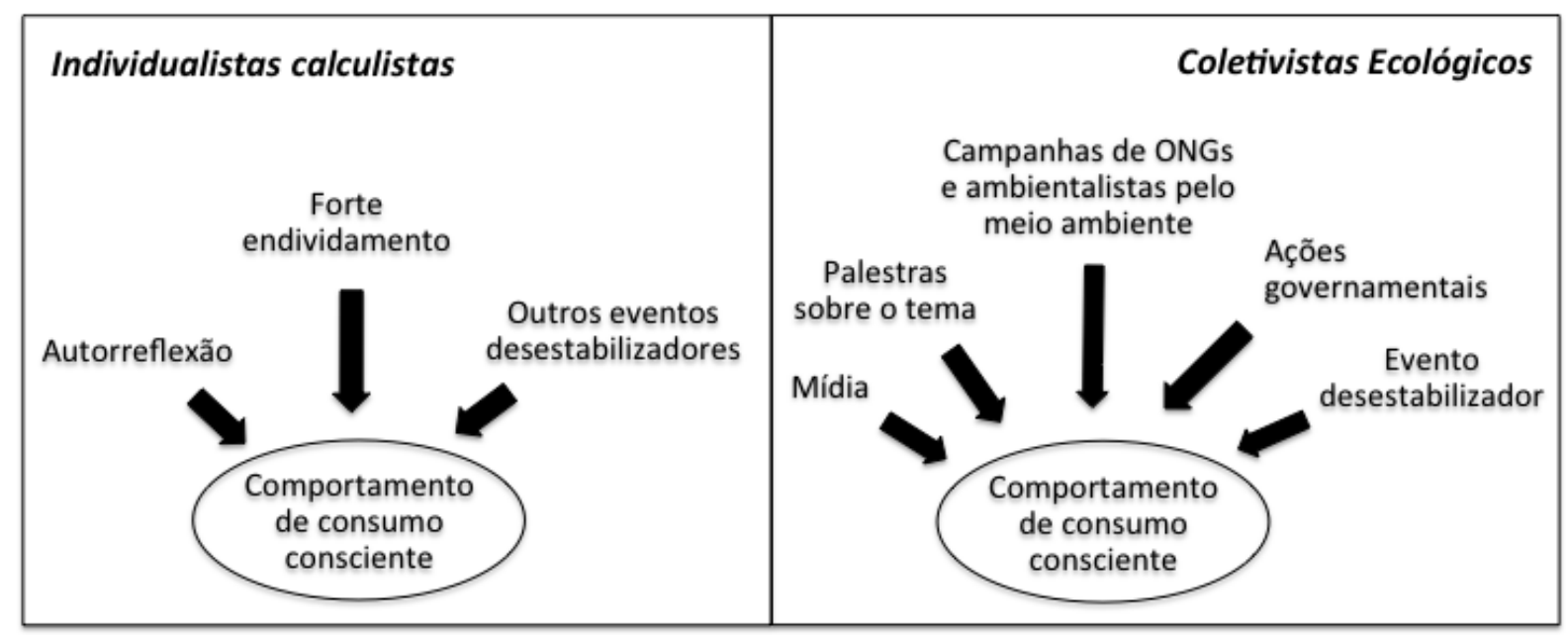

A análise das descrições das características da personagem sugere que os respondentes atribuem ao consumidor consciente status distintivo: Ana possui educação superior, "boa condição financeira" e "viaja para o exterior nas férias"; ela é "branca" ou "clara", bonita, tem "cabelos lisos" e "claros"iv . Além disso, o consumidor consciente é alguém que "vive num mundo real" e "pensa no futuro". Valoriza as pessoas, as amizades e a família. Busca bem-estar.

Mas o que faz de alguém um consumidor consciente? Por quais mudanças de hábitos este consumidor passa? Que atividades estão associadas ao consumo consciente? A figura 2 mostra que as mudanças de comportamento dos individualistas calculistas e dos coletivistas ecológicos guardam semelhanças e diferenças. Em grande medida, as semelhanças giram em torno do controle do consumo. É importante notar que algumas práticas/mudanças de hábitos que parecem comuns aos dois grupos - como comprar o necessário ou usar menos o automóvel - são citadas pelos respondentes com objetivos diferentes: para os individualistas calculistas estas práticas parecem puramente relacionadas ao controle financeiro, enquanto para os coletivistas ecológicos relacionam-se à redução dos impactos externos do consumo.

REMark - Revista Brasileira de Marketing, São Paulo, v. 11, n. 2, p. 18-42, maio/ago.2012. 
Figura 2 - Mudanças de comportamento atribuídas aos dois tipos de consumidores conscientes construídos pelos respondentes

\begin{tabular}{|c|c|}
\hline INDIVIDUALISTAS CALCULISTAS & COLETIVISTAS ECOLÓGICOS \\
\hline \multirow{3}{*}{$\begin{array}{l}\text { Controlar-se; comprar o necessário; fazer lista de } \\
\text { compras; evitar promoções; gastar de forma } \\
\text { racional }\end{array}$} & Ter uma alimentação saudável \\
\hline & Praticar exercícios \\
\hline & Poupar, evitar sair com cheques e cartão de crédito \\
\hline Redução do consumo & Fazer planejamento \\
\hline \multirow{2}{*}{$\begin{array}{l}\text { Forma de pagamento: Comprar à vista, sair com } \\
\text { dinheiro certo, aposentar o cartão de crédito, } \\
\text { cancelar cheque especial }\end{array}$} & $\begin{array}{l}\text { Controlar-se, Comprar o necessário, evitar o exagero, } \\
\text { Avaliar o custo x benefício das compras }\end{array}$ \\
\hline & Não desperdiçar, aproveitar melhor os alimentos \\
\hline Poupar; economizar; pedir descontos & $\begin{array}{l}\text { Informar-se sobre empresas e produtos, e seu impacto } \\
\text { no planeta, antes de consumir }\end{array}$ \\
\hline Saldar dívidas & \multirow{4}{*}{$\begin{array}{l}\text { Não desperdiçar água ou energia: fechar a torneira ao } \\
\text { lavar a louça ou escovar os dentes; eliminar } \\
\text { vazamentos; varrer a calçada ao invés de usar a } \\
\text { mangueira; diminuir tempo de banho e fechar o } \\
\text { chuveiro ao ensaboar-se; reduzir uso do ar } \\
\text { condicionado; apagar a luz quando ninguém está } \\
\text { utilizando. }\end{array}$} \\
\hline $\begin{array}{l}\text { Pesquisar preços, avaliar custo x benefício; mapear } \\
\text { despesas fixas e controlar o salário }\end{array}$ & \\
\hline $\begin{array}{l}\text { Trocar shopping por outros programas (praia, } \\
\text { parque); Reduzir programas caros, como } \\
\text { restaurantes. }\end{array}$ & \\
\hline Utilizar menos o carro & \\
\hline Dar valor ao dinheiro & $\begin{array}{l}\text { Comprar produtos orgânicos, alimentos com "Selo } \\
\text { Verde", Selo Procel. }\end{array}$ \\
\hline Pensar no amanhã & \multirow{3}{*}{$\begin{array}{l}\text { Comprar produtos biodegradáveis, de madeira } \\
\text { reflorestada, com pouca embalagem ou embalagem } \\
\text { econômica }\end{array}$} \\
\hline Viver mais com menos & \\
\hline Dar valor a si mesmo e às pessoas & \\
\hline Emagrecer & Separar lixo reciclável para a coleta seletiva \\
\hline Acordar cedo & Não jogar lixo na rua \\
\hline Estudar & Trocar a sacola plástica pela sacola de tecido \\
\hline Ocupar a mente com coisas saudáveis & Reutilizar ou doar pertences \\
\hline \multirow{3}{*}{ Dedicar mais tempo às filhas } & $\begin{array}{l}\text { Abandonar o carro; Utilizar bicicleta; Comprar carro a } \\
\text { biodiesel }\end{array}$ \\
\hline & $\begin{array}{l}\text { Reduzir utilização de papel, reutilizar papel e usar } \\
\text { papel reciclado }\end{array}$ \\
\hline & $\begin{array}{l}\text { Ativismo: criar de 'papa-pilhas' no condomínio, } \\
\text { boicotar empresas não-sustentáveis, conscientizar os } \\
\text { outros }\end{array}$ \\
\hline
\end{tabular}

É justamente com relação ao impacto das atividades citadas que os dois tipos de consumidores conscientes construídos pelos respondentes mais diferem. As mudanças de comportamento dos individualistas calculistas têm como objetivo retorno ou impacto positivo individual. Este consumidor não parece preocupado com o impacto de seu consumo no mundo exterior, ao contrário dos coletivistas ecológicos, cujas mudanças de comportamento citadas pelos respondentes denotam uma preocupação forte com o coletivo, notadamente com o meio ambiente. Embora muitas das práticas dos coletivistas ecológicos tenham claro impacto individual, coletivistas ecológicos parecem ter como foco da ação individual - ou seja, do consumo consciente - a busca de uma transformação externa. Entre eles, poucas são as 
mudanças com impactos predominantemente individuais, como a prática de exercícios ou a adoção de alimentação saudável.

Diferente do que Connolly e Prothero (2003) encontraram, é interessante notar que os relatos dos respondentes indicam que os coletivistas ecológicos percebem a questão ambiental para além da reciclagem e do lixo: os níveis de consumo também são encarados como problema e precisam ser reduzidos.

O coletivista ecológico se "preocupa com os outros" e pensa no "bem da humanidade" e, por isso, demonstra traços de ativista: quer conscientizar os outros, cria iniciativas e pratica o boicote. Ou seja, pretende influenciar a sociedade e mudar o mundo através do consumo (o 'consumo político' de Cherrier, 2009), o que indica que parte dos respondentes parece associar o consumidor consciente a atos políticos (Ozcaglar-Toulouse, 2007).

Um dos respondentes explica que a mudança de Ana foi fruto da "influência das pessoas com quem trabalha, que já são consumidores conscientes e tentam convencer a todos" enquanto outros informam que a personagem passou a fazer "palestras para conscientizar os vizinhos" e tenta "sensibilizar as outras pessoas com relação ao consumo consciente". Este caráter transformador do consumidor consciente coletivista ecológico também aparece quando um respondente conta que Ana passou a socializar-se com pessoas que pensam de forma semelhante a ela "a fim de aumentar o poder de barganha junto a fornecedores, governo e sociedade civil". É possível notar pelas mudanças de comportamento relatadas pelos informantes - tais como "abandonar o carro", "comprar produtos com selo verde" e "conscientizar os outros" -, que estes consumidores se utilizam de estratégias de saída, lealdade e voz (Ozcaglar-Toulouse, 2007).

Neste sentido, os coletivistas ecológicos poderiam se encaixar na ideia de "viver em um mundo incontrolável" (Cherrier, 2009), colocando o consumo como exaustão de recursos naturais. Por outro lado, os individualistas calculistas parecem mais próximos da visão de “solidão emocional" observada por Cherrier (2009). O consumo consciente seria, para eles, uma tentativa de transformação individual, uma resposta à vida em um "mundo vazio".

\subsection{O CONSUMO CONSCIENTE DIFICULTANDO A VIDA}

A mudança de hábitos na busca de um estilo de vida consciente é descrita pelos respondentes como "difícil". Consumir de forma consciente envolve hábitos que "dão trabalho" e exige "sacrifícios" - incluindo "abrir mão das coisas boas que estava acostumada" - e "muita força de vontade". É uma "batalha", que requer "derrubar barreiras" e "ultrapassar obstáculos".

REMark - Revista Brasileira de Marketing, São Paulo, v. 11, n. 2, p. 18-42, maio/ago.2012. 
Talvez por isto, diversos respondentes dotam a personagem de "personalidade forte" ou descrevem-na como uma pessoa "muito decidida".

Wheeler (2012), utilizando uma abordagem prático-teórica (Warde, 2005) para investigar o comércio justo, explica que as práticas que guiam o consumo cotidiano são apoiadas por toda uma gama de estruturas coletivas, incluindo normas culturais, discursos, contextos institucionais e infraestruturas de fornecimento. Ou seja, o consumo é moldado por estas estruturas compartilhadas e possivelmente esse é um dos aspectos que fazem com que a mudança de hábitos seja tão difícil.

Os respondentes percebem que o comportamento de consumo pode tanto afetar quanto ser afetado pelas relações pessoais do indivíduo. Amigos, colegas e parentes são apontados como influenciadores importantes seja do comportamento consciente seja do "inconsciente", como o caso das 'comprinhas com as amigas', por exemplo. O comportamento de consumo consciente pode gerar conflito nas relações sociais (Shaw \& Newholm, 2002; Szmigin et al., 2009). Para alguns respondentes, isto é uma das maiores dificuldades enfrentadas pelos consumidores conscientes: "o mais difícil é fazer com que os demais membros da família compreendam a nova filosofia de vida". Muitos informantes acreditam que "tudo que envolve os outros" é mais difícil, seja "mobilizar as pessoas", mudar "hábitos alheios" ou evitar tentações: "com pessoas ao lado, as tentações ficam mais difíceis de serem controladas".

Wheeler (2012) e Hargreaves (2011) enfatizam a importância das relações e redes sociais na produção e reprodução das práticas. Estas redes sociais estabelecem "normas sociais e expectativas específicas sobre o que constitui o comportamento apropriado" (Wheeler, 2012, p.137) e são importantes na geração de consciência e reconhecimento social de determinada prática, ao mesmo tempo em que oferecem ao indivíduo um senso de pertencimento. Daí a dificuldade de adotar um comportamento que foge às normas sociais dos grupos no qual o indivíduo está inserido.

Outra dificuldade envolvendo terceiros aparece quando as atividades em questão dependem de instituições ou de empresas. Um informante aponta que pode ser um problema "consumir produtos ecologicamente corretos" porque as empresas "não estão preparadas para oferecê-los" e "nem todas acordaram para a realidade". Outro informa a dificuldade do descarte de "pilhas, baterias e celulares", já que "não há sistema de recolhimento". Estas questões remetem à ideia de 'desempenhabilidade' (Wheeler, 2012) das práticas, que é restringida pelos contextos sociais e institucionais, pelas infraestruturas de fornecimento.

REMark - Revista Brasileira de Marketing, São Paulo, v. 11, n. 2, p. 18-42, maio/ago.2012. 
A separação de lixo para coleta seletiva também é incluída por alguns como uma das mudanças mais difíceis. Fato que pode ser justificado por esta prática implicar necessariamente na alteração de um comportamento praticamente automático: o descarte. Além disso, a separação de lixo parece ser vista como complicada por envolver a utilização de "diferentes lixeiras para cada tipo de resíduo" ou a "adaptação das lixeiras da casa" e por requerer, quando o município não está preparado para a coleta seletiva, esforços individuais significativos na busca por soluções alternativas como a "doação para ONGs de reciclagem”.

\section{DISCUSSÃO FINAL}

Este trabalho buscou auxiliar no entendimento dos discursos dominantes sobre o consumo consciente, investigando como o consumidor consciente, suas motivações, suas práticas e suas dificuldades são discursivamente construídos pelos demais consumidores. Esta perspectiva pode ser útil para ONGs e entidades que defendem o tema (e.g. Akatu, Idec), governos e empresas preocupadas com efeitos do consumo e que queiram estimular mudanças no comportamento dos consumidores.

Duas construções diferentes do consumo consciente foram identificadas nos relatos dos respondentes, dando origem a duas categorias distintas de consumidores conscientes: o individualista calculista e o coletivista ecológico. A grande diferença entre estes dois consumidores conscientes está em seu foco de ação. Enquanto o primeiro, descrito fortemente em termos de busca por controle financeiro, muda seu comportamento em busca de recompensas individuais, o segundo apresenta preocupações ambientais e sociais, está preocupado com os impactos de seu consumo no mundo exterior e parece querer transformar o mundo através do consumo.

Ao contrário do consumidor consciente coletivista ecológico, o individualista calculista mostra-se incongruente com as descrições que literatura tem trazido. O fato de parte dos informantes construírem o consumo consciente como o oposto da compulsão por consumo e do descontrole financeiro parece sugerir que o termo ainda não foi bem assimilado pelo público. $\mathrm{O}$ discurso deste grupo pode ter sido estimulado pelas comuns tentativas da mídia televisiva e impressa em guiar ou educar o consumidor no sentido de evitar ou resolver situações de endividamento.

REMark - Revista Brasileira de Marketing, São Paulo, v. 11, n. 2, p. 18-42, maio/ago.2012. 
Chama atenção também o fato dos respondentes construírem o comportamento de consumo em termos de uma forte dualidade entre 'inconsciente' e consciente. Os relatos sugerem que ou o consumidor é consciente ou não é, apesar da literatura apontar para certa flexibilidade deste consumidor (e.g. Szmigin et al, 2009; Shaw e Newholm, 2002; Wheeler, 2012). O "consumidor inconsciente" surge como uma categoria que pode merecer estudos futuros.

$\mathrm{Na}$ visão dos informantes, o consumidor coletivista ecológico precisa estar informado, ter acesso à informação. Com base na discussão feita neste trabalho, sugere-se que instituições, governos ou mesmo empresas preocupadas com sustentabilidade e impactos socioambientais do consumo invistam mais na disponibilização de informações para o público. Isto significa informação de fácil acesso e fácil entendimento. Mas, em um momento em que, diz-se, as pessoas nunca estiveram expostas a tamanho volume de informações e estímulos diários (Bauman, 2008), parece ser necessário também tornar atraentes as informações sobre impactos do consumo e práticas de consumo consciente. De outra forma, tais esclarecimentos ficarão restritos àqueles que realmente queiram encontrá-los.

Mas, a disponibilidade de informações parece não ser suficiente. Os achados fortalecem a argumentação de Cherrier (2005) quanto à importância dos eventos fundadores (OzcaglarToulouse, 2007) na internalização do comportamento ético. Alguns relatos também atribuem a opção por uma nova "filosofia de vida" a experiências desestabilizadoras, causadoras de uma profunda emoção (Cherrier, 2005). Talvez por isso, muitos dos respondentes, apesar de mostrarem-se razoavelmente informados a respeito do tema - incluindo aí a "escassez de recursos naturais" colocada por um deles -, não dão sinais de seguirem os passos do consumo consciente. Se é preciso uma 'experiência transformadora', o que organizações que trabalham o tema podem fazer?

Uma sugestão seria a promoção de eventos que busquem maior envolvimento do consumidor que já possui informações sobre o tema, de forma a causar maior impacto emocional. Possivelmente uma visita a um lixão ou atividades que despertem a percepção para a quantidade de lixo gerada diariamente, por exemplo, podem sensibilizar mais o consumidor do que simplesmente leituras ou filmes sobre o assunto.

Outros pontos importantes expostos pelos respondentes incluem a dificuldade em mudar hábitos e alterar práticas não apenas por conta de 'costume' mas também das relações sociais. Wheeler (2012) aponta que as mudanças de comportamento apenas através do fornecimento de

REMark - Revista Brasileira de Marketing, São Paulo, v. 11, n. 2, p. 18-42, maio/ago.2012. 
informações são improváveis e ressalta a importância das experiências e compromissos passados (ou seja, a trajetória de vida) e das redes de relações sociais na alteração de práticas.

Isto parece indicar que introduzir conceitos e comportamentos de consumo consciente nos primeiros estágios da vida do indivíduo é fundamental. Portanto, informação e educação nas escolas - ou mesmo através de entretenimento infantil - soam como um caminho promissor. Experiências pontuais deste tipo já existem, mas poderiam ser expandidas através de uma ação coordenada.

Os relatos dos respondentes também apontam para a relevância das redes de relações sociais. Novos hábitos de consumo podem ser benéficos para a "humanidade", mas também podem gerar conflitos familiares e afastar o indivíduo do seu convívio social. Se um dos benefícios simbólicos do consumo está relacionado à aceitação, pertencimento e relacionamentos (Belk, 1988; Ferla \& Silveira, 2008), as respostas obtidas neste estudo sugerem que o consumo consciente parece suprimir estes benefícios, atuando, inclusive, em sentido contrário: tornandose fonte de conflitos de relacionamentos. Como Hargreaves (2011) e Wheeler (2012) levantam, o esforço em termos de motivar mudanças de comportamento devem deixar de focar nas pessoas enquanto consumidores individuais e passar a agir no nível coletivo. Desta forma, sugere-se que ONGs, governos e empresas sustentáveis redirecionar seus esforços a famílias e comunidades, buscando o envolvimento de todos os seus integrantes.

Por fim, acreditamos que o esforço de compreender o consumo consciente tem a ganhar com estudos que tragam uma abordagem prático-teórica (ver Warde, 2005). Esta perspectiva sobre o tema mostra-se interessante por colocar o foco nos processos de consumo e no exame de como práticas são aprendidas, desempenhadas e evoluem no contexto da vida cotidiana (Warde, 2005). Focar na "desempenhabilidade" (Wheeler, 2012) das práticas e como são negociadas e moldadas pelos contextos sociais e institucionais pode auxiliar o desenho de ações de ONGs, empresas e de políticas públicas.

REMark - Revista Brasileira de Marketing, São Paulo, v. 11, n. 2, p. 18-42, maio/ago.2012. 


\section{REFERÊNCIAS}

Barros, D. F., \& Ayrosa, E. (2012). Consumo consciente: entre resistência do consumidor e discurso identitário. Anais do Encontro de Marketing da ANPAD, Curitiba, PR, Brasil, 5.

Barros, D. F., \& Costa, A. M. (2008). Consumo consciente no Brasil: um olhar introdutório sobre as práticas de resistência ao consumo por meio da análise do discurso do Instituto Akatu pelo Consumo Consciente. Anais do Encontro Nacional da Associac

- Graduac

, Rio de Janeiro, RJ, Brasil, 32.

Barros, D. F., Tucci, F., \& Costa, A. M. (2010). A Redenção do Consumo: o Caráter Denegatório do 'Consumo Consciente'. Anais do Encontro de Marketing da ANPAD, Florianópolis, SC, Brasil, 4.

Bauman, Z. (2008). Vida para consumo: a transformação das pessoas em mercadorias. Rio de Janeiro: Jorge Zahar Ed..

Belk, R. (1988). Possessions and the extended self. Journal of Consumer Research, 15(2), 139168.

Belk, R., Devinney, T., \& Eckhardt, G. (2005). Consumer Ethics Across Cultures. Consumption, Markets and Culture, 8(3), 275-289.

Cherrier, H. (2005). Becoming Sensitive to Ethical Consumption Behavior: Narratives of Survival in an Uncertains and Unpredictable World. Advances in Consumer Research, 32, 600-604.

Cherrier, H. (2006). Consumer identity and moral obligations in non-plastic bag consumption: a dialectical perspective. International Journal of Consumer Studies, 30(5), 515-523.

Cherrier, H. (2007). Ethical consumption practices: Co-production of self-expression and social recognition. Journal of Consumer Behaviour, 6(5), 321-335.

Cherrier, H. (2009). Anti-consumption discourses and consumer-resistant identities. Journal of Business Research, 62(2), 181-190.

Connolly, J., \& Prothero, A. (2003). Sustainable Consumption: Consumption, Consumers and the Commodity Discourse. Consumption, Markets and Culture, 6(4), 275-291.

Connolly, J., \& Prothero, A. (2008). Green Consumption: Life-politics, risk and contradictions. Journal of Consumer Culture, 8(1), 117-145, 2008.

Etzioni, A. (2004). The Post Affluent Society. Review of Social Economy, LXII(3), 407-420.

Ferla, D. A., \& Silveira, T. (2008). A relação entre os benefícios simbólicos do consumo e a formação da identidade dos jovens consumidores através de uma abordagem metodológica mista. Anais do Encontro de Marketing da ANPAD, Curitiba, PR, Brasil, 3.

REMark - Revista Brasileira de Marketing, São Paulo, v. 11, n. 2, p. 18-42, maio/ago.2012. 
Gummeson, E. (2005). Qualitative research in marketing - road-map for a wilderness of complexity and unpredictability. European Journal of Marketing, 39(3/4), 309-327.

Hall, S. (1997) The work of representation. In: S. Hall (org.). Representation: Cultural Representations and Signifying Processes. Londres: Sage.

Hargreaves, T. (2011). Practice-ing behaviour change: Applying social practice theory to proenvironmental behaviour change. Journal of Consumer Culture, 11(1), 79-99.

Harrison, R., Newholm, T., \& Shaw, D. (2005). The Ethical Consumer. Londres: SAGE.

Huneke, M. E. (2005). The Face of the Un-Consumer: An Empirical Examination of the Practice of Voluntary Simplicity in the United States. Psychology \& Marketing, 22(7), 527-550.

Kozinets, R. V., \& Handelman, J. M. (2004). Adversaries of Consumption: Consumer Movements, Activism, and Ideology. Journal of Consumer Research, 31(3), 691-704.

Levy, S. (1994). Interpreting consumer mythology: structural approach to consumer behavior focuses on story telling. Marketing Management, 2(4), 4-9.

McDonald, S., Oates, C. J., Young, C. W., \& Hwang, K. (2006). Toward Sustainable Consumption: Researching Voluntary Simplifiers. Psychology \& Marketing, 23(6), 515534.

Miller, D. (2007). Consumo como cultura material. Horizontes Antropológicos, 13(28), 33-63.

Moisander, J., Pesonen, S. (2002). Narratives of sustainable ways of living: Constructing the self and the other as a green consumer. Management Decision, 40 (4), 329-342.

Ozcaglar-Toulouse, N. (2007). Living For "Ethics": Responsible Consumption in Everyday Life. In: BELK, R.; SHERRY, J. Research in Consumer Behavior (Vol. 11, pp. 393-409) Oxford: Elsevier.

Pepper, M., Jackson, T., \& Uzzell, D. (2009). An examination of the values that motivate socially conscious and frugal consumer behaviours. International Journal of Consumer Studies, 33(2), 126-136.

Ritson, M., \& Dobscha, S. (1999). Marketing heretics: resistance is/is not futile. Advances in Consumer Research, 26, 159.

Shaw, D., \& Newholm, T. (2002). Voluntary Simplicity and the Ethics of Consumption. Psychology \& Marketing, 12(2), 167-185.

Spiggle, S. (1994). Analysis and interpretation of qualitative data in consumer research. Journal of Consumer Research, 21(3), 491-503.

Szmigin, I., \& Carrigan, M. (2006). Exploring the Dimensions of Ethical Consumption. European Advances in Consumer Research, 7, 608-613.

REMark - Revista Brasileira de Marketing, São Paulo, v. 11, n. 2, p. 18-42, maio/ago.2012. 
Szmigin, I., Carrigan, M. \& McEachern, M. G. (2009). The conscious consumer: taking a flexible approach to ethical behavior. International Journal of Consumer Studies, 33(2), 224-231.

Warde, A. (2005). Consumption and Theories of Practice. Journal of Consumer Culture, 5(2), 131-153.

Wheeler, K. (2012). The practice of Fairtrade support. Sociology, 46(1), 126-141.

Will, V., Eadie, D., \& Macaskill, S. (1996). Projective and enabling techniques explored, Marketing Intelligence \& Planning, 14(6), 38-43.

Worldwatch Institute (2010). Estado do Mundo 2010: Transformando Culturas do Consumismo à Sustentabilidade. Washington: UMA Editora. (disponível em: http://www.akatu.org.br/akatu_acao/publicacoes/reflexoes-sobre-o-consumo-consciente)

Zavestoski, S. (2002). The Social-Psychological Bases of Anticonsumption Attitudes. Psychology \& Marketing, 19(2), 149-165.

\footnotetext{
${ }^{\mathrm{i}_{\mathrm{i}}}$ Chamamos de novo consumidores aqueles preocupados com o efeito de suas compras no mundo exterior.

ii “O Instituto Akatu é uma organização não governamental sem fins lucrativos que trabalha pela conscientização e mobilização da sociedade para o Consumo Consciente" (http://www.akatu.org.br/Institucional/OAkatu). O Akatu "defende o ato de consumo consciente como um instrumento fundamental de transformação do mundo, já que qualquer consumidor pode contribuir para a sustentabilidade da vida no planeta: por meio do consumo de recursos naturais, de produtos e de serviços e pela valorização da responsabilidade social das empresas" (http://www.akatu.org.br/Institucional/OAkatu). É interessante observar que o Instituto foi criado, em 2000, no seio de um representante de empresas privadas - o Instituto Ethos de Empresas e Responsabilidade Social - e não por consumidores (BARROS; COSTA, 2008).

iii Alcoólicos Anônimos.

${ }^{\text {iv }}$ Para uma discussão sobre cabelos loiros e lisos como símbolo de status social no Brasil ver: (1) Bouzón, P. (2008). Cabelos e construção de identidades: incursão antropológica em um salão de beleza. In: L. Casotti, M. Suarez, \& R.D. Campos (org) O tempo da beleza: consumo e comportamento feminino, novos olhares. Rio de Janeiro: Senac Nacional. (2) Sabino, C. (2007). A louridade da loura. In: M. Goldenberg, (org.). O corpo como capital: estudos sobre gênero, sexualidade e moda na cultura brasileira. Barueri, SP: Estação das Letras e Cores
} 